\title{
Average Conditional Volatility: A Measure Of Systemic Risk For Commercial Banks
}

\author{
Harikumar Sankaran, New Mexico State University, USA \\ Manish Saxena, Sandia Investment Group of Wells Fargo Advisors, USA \\ Christopher A. Erickson, New Mexico State University, USA
}

\begin{abstract}
We propose using the cross-sectional (daily) average conditional volatility of commercial bank stock returns as a measure of systemic risk for the U.S. banking industry. The performance of this measure is tested using data from the 2008 pre-crisis period. The measure is shown to incorporate individual bank risk as well as the cumulative riskiness of a cross-section of banks. Crosssectional regressions indicate that individual bank's probability of default is unrelated to the bank's conditional volatility during times of low, industry wide risk (as measured by average conditional volatility). However, the bank's conditional volatility significantly affects its probability of default when the industry is experiencing a high level risk. Regardless of the industry level risk, a bank's probability of default has a significant negative relation with its capital adequacy (as measured by the proportion of equity capital). Additionally, at an aggregate level, Granger causality tests indicate that the conditional volatility of 'big' banks causes the riskiness of medium and small banks to increase.
\end{abstract}

Keywords: Systemic Risk; GARCH; Conditional Volatility; Banking

\section{INTRODUCTION}

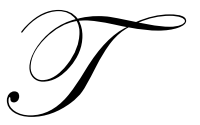

he financial crisis that began in 2008 has made clear that evaluating systemic risk is an important issue facing regulators and other stake holders in the banking system. Risk measures such as distance to default and probability of default at an individual bank level have been proposed. These measures do not provide systemic information and rely partly on accounting data that is infrequently available. In this paper, we empirically examine the information content of average volatility of commercial bank stock returns and characterize its relation to industry level risk and individual bank-level risk. This measure is easy to implement and makes it attractive to regulators seeking to detect abnormality in systemic risk in a timely manner.

Systemic risk refers to the risk that the financial system taken as a whole will suffer losses thereby imposing losses on investors that would not otherwise occur if the financial system continued to operate normally. It involves the correlation among several parts of the financial system so that losses in one element imply losses in other elements [Kaufmann and Scott (2003); Bartholomew and Whalen (1995)]. In banking, systemic risk is manifested by high correlation and clustering of bank distress or bank failures in a single country, or internationally. Systemic risk can arise when a bank or other financial institution fails, which then has knock on effects on other banks. These knock on effects can be propagated either through direct exposure of a number of banks to the failed bank or fear that the other banks hold similar or identical portfolios to the failed institution. The latter sort of situation can lead to liquidity crisis as investors seek to withdraw from the affected institutions. ${ }^{1}$ Schwarcz (2008) synthesizes these ideas in the following definition "[S]ystemic risk is the risk that an economic shock such as market or institutional failure triggers (through panic or otherwise) either the failure of a chain of markets and institutions or a chain of significant losses to financial institutions, resulting in increases in the cost of capital or decreases in availability, often evidenced by substantial financial-market price volatility".

\footnotetext{
${ }^{1}$ See Kaufman and Scott (2003) for a discussion of various definitions of systemic risk.
} 
The above definitions suggest that any measure of systemic risk must reflect the risk of an individual bank, and the influence that single bank's performance has on other institutions. In a recent paper, Acharya et al (2010) model systemic risk based on individual bank risk and its contribution to the systemic risk. In the presence of limited liability, each bank stands to lose their net worth in case of a default. This loss is called default expected shortfall at the individual bank level. They define systemic risk event as one where the aggregate value of net worth drops below a target level (a fraction of assets). In this context, the expected shortfall that represents the amount by which a bank's equity drops below its target level (a fraction of assets) is considered the marginal contribution of that bank to the systemic risk. Acharya et al suggest that systemic risk conditional on macro-economic events can be measured by the long-run volatility models. Brownlees and Engle (2010) apply Acharya et al (2010) model to data from the current crisis and report weekly systemic risk analysis. ${ }^{2}$ These authors compute annualized volatility series averages by industry group and find that volatility gradually surges as the financial crisis begins in 2008 .

We take a different approach by estimating conditional volatilities using a GARCH. We make several important contributions to the literature. First, from cross-sectional regressions we find that the individual bank's probability of default is not influenced by its conditional volatility of stock returns when the average conditional volatility of the industry is low. Our results indicate that the bank-level conditional volatility of stock returns significantly affects the individual bank's probability of default when the industry level risk is high. This finding is important because it highlights the important link between risk at the bank level and at the industry level. We also find that, regardless of the industry level risk, the bank's probability of default decreases as the proportion of equity in the bank capital increases. Second, in order to verify whether conditional volatility reflects the influence of the failure of a single bank or institution has on other institutions, we calculated the time-series of average conditional volatility for large, medium and small sized banks and conducted a Granger causality test. We found that causality flows from banks with a high market value of equity to medium and small sized bank. ${ }^{3}$

The paper is laid out in the following manner. Section 2 contains the motivation and describes the estimation of average conditional volatility. This section also describes the time-series of average conditional volatility during 2007 and 2008. Section 3 contains results from regression analysis that shows how industry level risk impacts the relation between the individual bank's probability of default, bank-level conditional volatility and capital adequacy. Section 4 presents the time-series of average conditional volatility for large and small sized banks and results from the Granger causality test. Our concluding remarks are in Section 5.

\section{MOTIVATION AND ESTIMATION OF SYSTEMIC RISK}

We examine aggregate bank return volatility to analyze the types of information (and risk) it captures. Consider the following $\operatorname{GARCH}(p, q)$ return generating process ${ }^{4}$

$$
\begin{gathered}
r_{i t}=\mu_{i}+e_{i t}, \\
e_{i t} \sim N\left(0, \sigma_{i t}{ }^{2}\right), \\
\sigma_{i t}{ }^{2}=\alpha_{i}+\sum_{j=1}^{q} \beta_{i j} e_{i, t-j}^{2}+\sum_{j=1}^{q} \gamma_{i j} \sigma_{i, t-j}^{2}
\end{gathered}
$$

where $r_{i t}$ denotes the return, $\mu_{i}$ denotes the mean return, $e_{i t}$ denotes the unexpected innovation in the return, and $\sigma_{i t}^{2}$ denotes the conditional volatility. The subscript $t$ denotes time and the subscript $i$ denotes bank. The conditional volatility in equation (1) depends on the lag structure for innovations in returns. Volatility clustering is modeled by the third term on the right, where periods of higher volatility in the past propagates a higher volatility in the current period. Thus, the conditional volatility contains information about the bank's current and past unexpected performance and the combined risk as measured by volatility associated with of such innovations.

\footnotetext{
${ }^{2}$ See the risk section of the Vlab (http://www.systemicriskranking.stern.nyu.edu/).

${ }^{3}$ Our research is related to previous work that seeks to model individual bank risk [Merton (1977), Markus and Shaked (1984), Gennotte and Pyle (1991) Moody's (2003); Bharath and Shumway (2008), and Chan-Lau and Amadou (2006)] and research that is aimed at measuring risk to captures the interrelatedness between banks [Lehar (2005), Gray, Merton and Bodie (2008) and Gray and Jobst (2009)].

${ }^{4}$ See Engle (1982); Bollerslev(1986); Bollerslev, Chou and Kroner (1992).
} 
We can use the risk faced by an individual bank to construct a measure of systemic risk. To see this, consider a banking industry consisting of two banks with daily returns characterized by a $\operatorname{GARCH}(1,1)$ process. The conditional volatility for Banks 1 and 2 are given by

$$
\left[\begin{array}{c}
\sigma_{1 t}{ }^{2} \\
\sigma_{2 t}{ }^{2}
\end{array}\right]=\left[\begin{array}{l}
\alpha_{1} \\
\alpha_{2}
\end{array}\right]+\left[\begin{array}{l}
\beta_{1} e^{2}{ }_{1, t-1} \\
\beta_{2} e^{2}{ }_{2, t-1}
\end{array}\right]+\left[\begin{array}{l}
\gamma_{1} \sigma_{1, t-1}^{2} \\
\gamma_{2} \sigma_{2, t-1}^{2}
\end{array}\right] .
$$

The cross-sectional average conditional volatility is computed as

$$
\sigma_{t}^{2}=\frac{\left(\alpha_{1}+\alpha_{2}\right)}{2}+\frac{\left(\beta_{1} e_{1, t-1}^{2}+\beta_{2} e_{2, t-1}^{2}\right)}{2}+\frac{\left(\gamma_{1} \sigma_{1, t-1}^{2}+\gamma_{2} \sigma_{2, t-1}^{2}\right)}{2}
$$

Suppose now that specific information about Bank 1 arrives indicating a reduced return at the end of period $t-1$. This is quickly reflected in stock price, causing a negative value for the innovation, $e_{1, t-1}$ at time $t-1$. This bank specific event is reflected in $\sigma_{t}^{2}$ through the second RHS term of equation (3). It may be also that returns of the Bank 1 and Bank 2 are correlated. Such a correlation could arise from a number of causes: 1) a common macro-shock affecting both banks; 2) directly by holding of Bank 1 securities by Bank 2; and 3) indirectly via common third party exposure [Kaufman and Scott (2003)]. A poor performance by Bank 1 not only causes $e_{1, \mathrm{t}-1}$ to be large and negative but also may have an impact on $e_{2, \mathrm{t}-1}$. The cross-sectional average conditional volatility reflects the correlation between innovations by considering its long term impact on individual bank volatility. Thus, Equation (3) gives a measure of both individual risk as well as systemic risk.

We can generalize Equation (3) to apply to an industry with $n$ banks as:

$\sigma_{t}^{2}=\sum_{i=1}^{n} \frac{\alpha_{i}+\beta_{i} e^{2}{ }_{i, t-1}+\gamma_{i} \sigma_{i, t-1}^{2}}{n}$

The measure in equation (4) is a systemic measure of risk as it considers the risk of an individual bank, and the influence the individual bank has on other institutions. This system-wide measure can be computed daily using market data thus affording the desirable feature of timely intervention.

We draw the data for 344 banks from the Chicago Research in Security Prices (CRSP) database and from the Standard and Poors' Compustat database. For each of the 344 banks in our sample, we use 252 daily returns from the year 2007 to estimate the coefficients $\alpha_{\mathrm{i}}, \beta_{i}$, and $\gamma_{i}$ in a $\operatorname{GARCH}(1,1)$ model where the volatility for bank $i$ at time $t$ is given as $\sigma_{i t}{ }^{2}=\alpha_{i}+\beta_{i} e_{i, t-1}^{2}+\gamma_{i} O_{i, t-1}^{2} .^{5}$ Each innovation $e_{i t}$ is the difference between the actual return on day $t$ for bank $i$ (denoted as $r_{i t}$ ) and the corresponding expected return $\mu_{i t}$. The expected daily return during 2008 is calculated on the basis of a moving average method trailing 252 trading days. As everyday evolves the oldest return is dropped from the time series and the most recent return is added to calculate a new mean. In particular,

$\mu_{i t}=\frac{\left(\mu_{i, t-1}\right) * 252+r_{i t}-r_{i, t-252}}{252}$ for $t=1, \ldots, 180$,

\footnotetext{
${ }^{5}$ Our purpose here is to study the use of conditional volatility as a measure of systemic risk. We consider GARCH $(1,1)$ merely as an example and do not investigate the model of best fit. However, prior research has shown that GARCH $(1,1)$ fits the data well. Hansen and Lunde (2001) use the DM-USD exchange rate data and compare the forecasting ability of several GARCH type models. They find that none of the models beat GARCH $(1,1)$ in its forecasting ability. Duan and Wei (1999) find that GARCH $(1,1)$ fits the data on the underlying asset for currency options.
} 
where, $\mu_{i, t-1}=\frac{1}{252} \sum_{j=1}^{252} r_{i, t-j}$, for $t=1, \ldots, 180$, for $i=1, \ldots, 344$. We estimate $\sigma_{i t}{ }^{2}$ for the first 180 trading days (about nine months) in $2008 .{ }^{6}$ In estimating the evolution of conditional volatility, we assume that the initial conditional volatility for each bank $\left(\sigma_{i 0}{ }^{2}\right)$ is the average (daily) historical volatility for that bank computed from the 2007 returns. Figures (1) shows a plot of the average conditional volatility across 344 banks for each of the first 180 trading days in 2008 .

Figure (1): This figure plots the cross-sectional average conditional volatility during the first 180 trading days in 2008 . The coefficients of a GARCH $(1,1)$ model are computed for each of the 344 banks using the 2007 returns data. These coefficients are applied to the 2008 returns data to compute the conditional volatility for each bank. The cross-sectional average for each day is plotted in the following figure. This period is broadly characterized by at least three volatility clusters denoted as A, B and C.

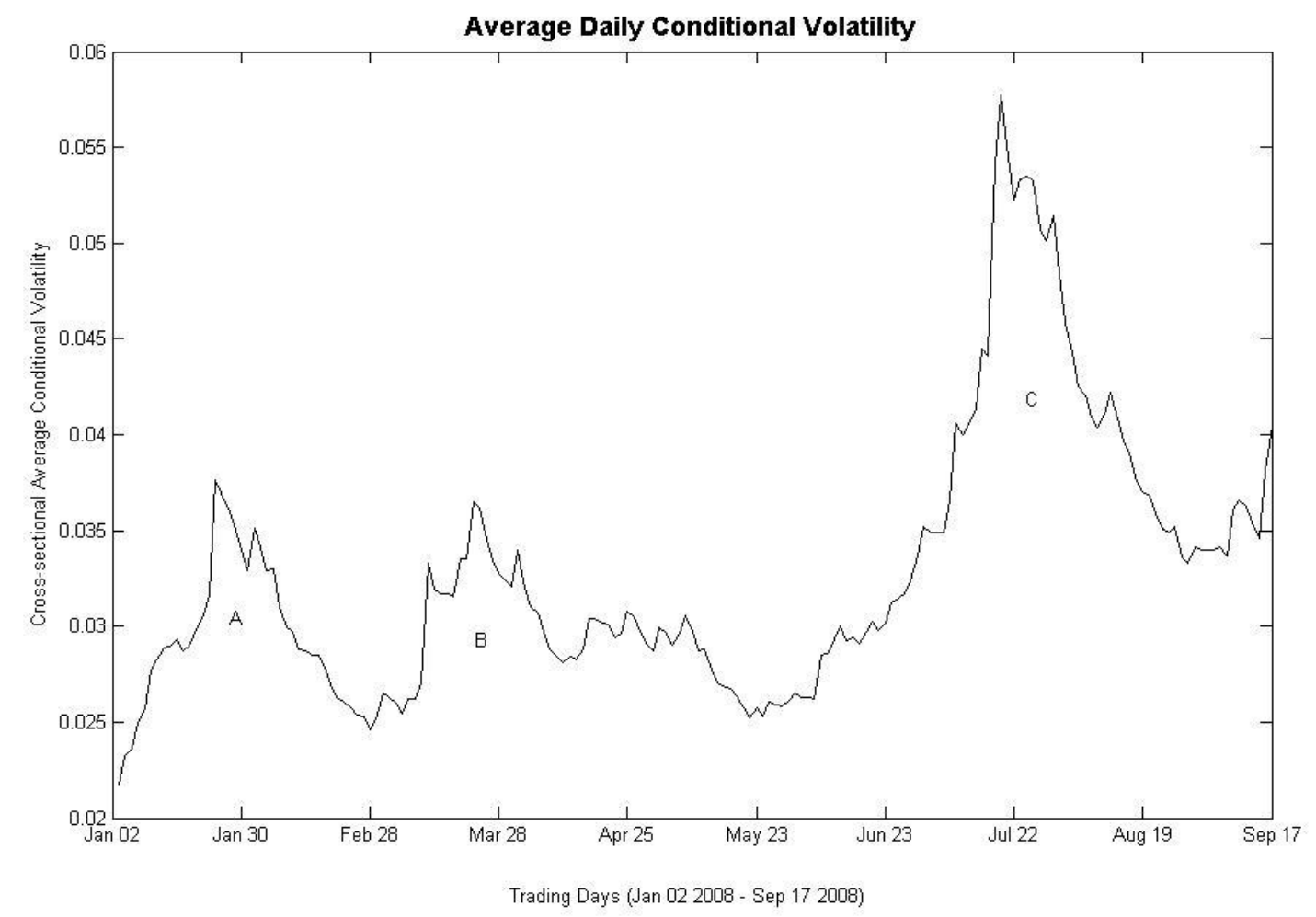

The $x$-axis represents the calendar dates during the first 180 trading days in 2008. The $y$-axis represents the cross-sectional average conditional volatility computed as $\sum_{i=1}^{344} \sigma_{i t} / 344$.

On Figure 1 are indicated three peaks in industry volatility denoted Cluster A, B and C. These clusters represent significant increases in systemic risk. For example, the average daily conditional volatility on the first trading day in 2008 is $2.18 \%$. The corresponding annualized volatility assuming 252 trading days is $34.6 \%$ $(2.18 \% \mathrm{x} \sqrt{252})$. The peak annualized volatility then increased to $59.75 \%$ on the $16^{\text {th }}$ trading day of 2008 , denoted as

\footnotetext{
${ }^{6}$ The crisis started unfolding around the beginning of September 2008. Our research focuses on the ability of conditional volatility serving as a measure of systemic risk. For this measure to be useful, it should be able to detect symptoms of the systemic risk much earlier than when events are precipitated in the economy. Hence, we choose the first 180 day trading period during 2008 that starts on January 2, 2008 and ends on September 17, 2008.
} 
Cluster A in Figure 1. Cluster B was also marked by a higher than average volatility with the peak annualized volatility of $57.94 \%$ on the $56^{\text {th }}$ trading day in 2008 . By the $138^{\text {th }}$ trading day, the annualized volatility had reached a high of $91.64 \%$ in Cluster C. Based on observing the trend in the first few weeks of 2008 it is quite evident that the banking industry was getting riskier. Since information on each bank is incorporated every day, the average conditional volatility provides the stakeholders with timely information.

We use the same procedure to compute the average conditional volatility for 2007. Figure (2) plots the volatilities for 2007 and 2008. The first 180 trading days in 2007 shows a daily volatility of less than $2 \%$ (annualized $31.7 \%$ ). The average volatility during the first 180 days in 2008 was consistently higher than the volatility for the same period in 2007. It is interesting to note that the average volatility increases towards the end of six months during both 2007 and 2008; a period just prior to the release of the accounting reports.

Figure (2): This figure plots the cross-sectional average conditional volatility during the first 180 trading days in 2007 and 2008. The coefficients of a GARCH $(1,1)$ model are computed for each of the 344 banks using the 2006 and 2007 returns data, respectively. These coefficients are applied to 2007 and 2008 returns data to compute the conditional volatility for each bank. The cross-sectional average for each day in 2007 and 2008 are plotted in the following figure.

Average Conditional Volatility 2007-2008

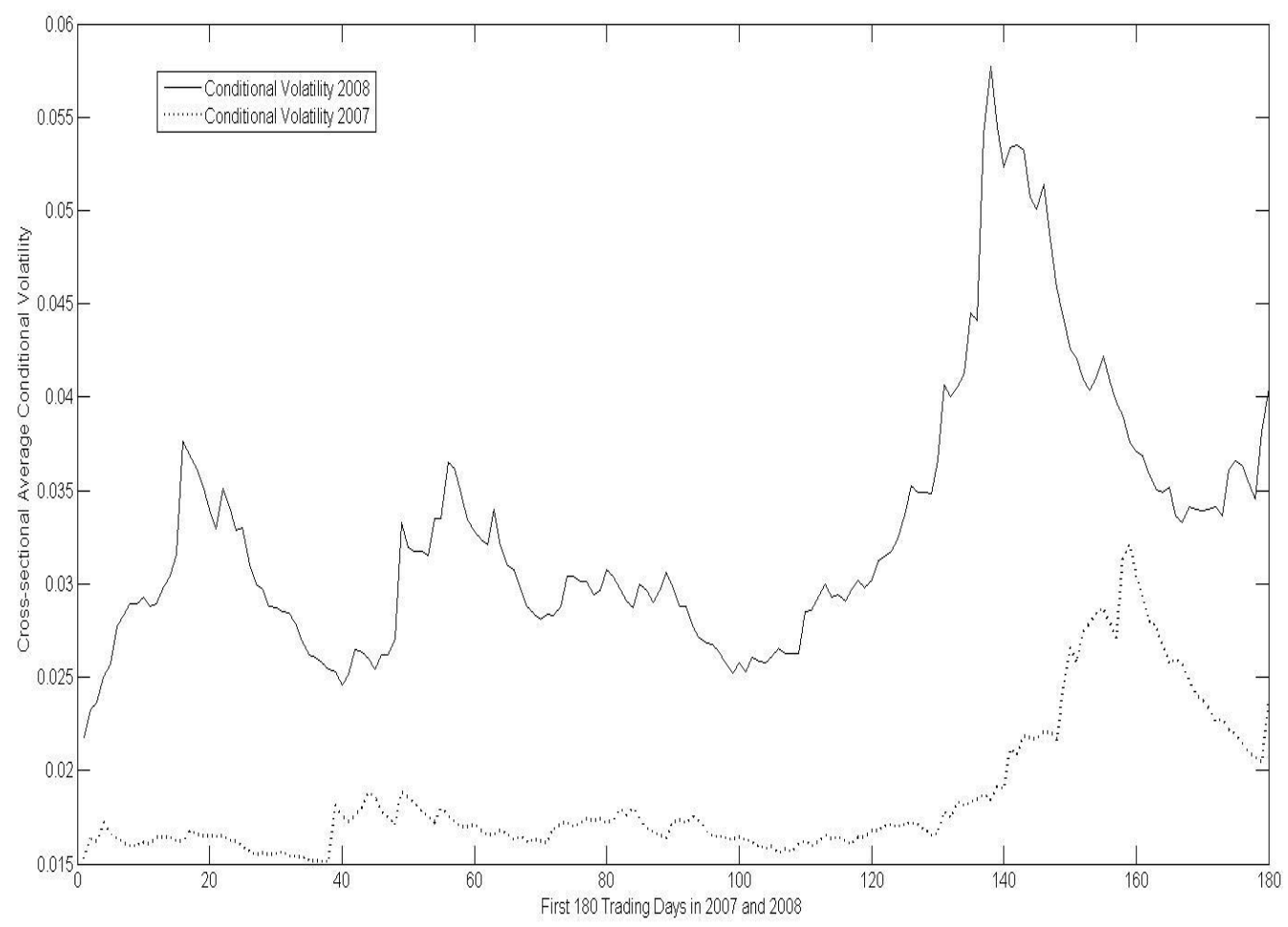

A measure of systemic risk must reflect the risk of an individual bank as well as its' influence on other institutions. This idea is illustrated in equation (4) and depicted in Figure (3). The plots in figure (3) reflect cumulative risks. The lowest plot indicates the amount of the cross-sectional average of the lagged conditional variance. This type of risk accounts for return innovations in prior periods and is the largest component of the total average conditional volatility. The second plot from the bottom indicates the cumulative risk of the lagged conditional variance and the cross-sectional average of return innovations for the day $t-1$. This second component reflects the impact of the most recent performance of a cross-section of banks. Finally, adding a model constant gives the estimate of the total volatility. Figure (3) shows that the lagged conditional variance (i.e., the systemic component) of the total volatility is responsible for the overall risk of the banking industry. Hence, we propose using 
the average conditional volatility as a measure of systemic risk in the banking industry. In the following sections, we empirically examine how the conditional volatility relates to individual bank risk and to risk at the systemic level.

Figure (3): This figure plots the components of the cross-sectional conditional variance during the first 180 trading days in 2008. The average variance on day $t$ consists of the average lagged innovations and the average lagged variances across 344 banks. The figure represents the cumulative sum of component risks. The largest component is the lagged conditional variance followed by the lagged innovations.

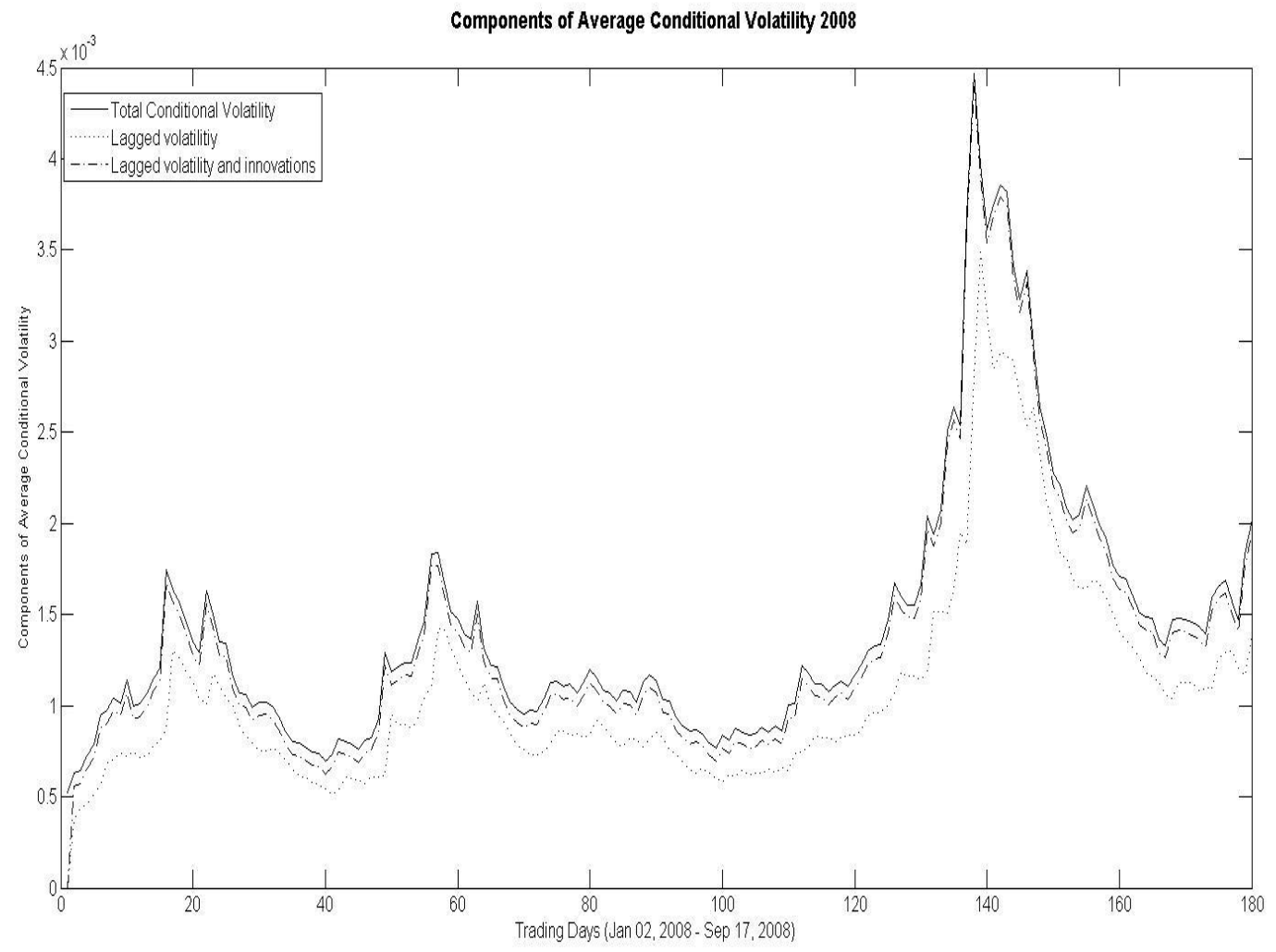

\section{SYSTEMIC RISK AND INDIVIDUAL BANK RISK}

In this section we use cross-sectional regressions to examine the relationship between individual bank risk (estimated by its probability of default) and variables such as the bank's conditional volatility and its individual risk characteristics. An obvious factor affecting individual bank risk is capital adequacy. The "safety net" theory posits that a bank's capital forms a kind of cushion against losses for depositors in that initial loss is absorbed by equity; only when equity is exhausted will depositors and other debt holders face expose. As a consequence, the risk to uninsured depositors, the deposit insurer, and other bank debt holders decrease with increases in capital requirements. Regulators have always considered capital adequacy standards as a concern and tool to mitigate risk at the level of the individual bank and the system as a whole. Capital adequacy also affects individual bank risk via its affect on the willingness of bank management to take on risk by introducing moral hazard. If banks do not have sufficient equity "at stake" when they make their investment decisions, they may make decisions which, though optimal for equity holders, are suboptimal from the point of view of society as a whole [Morrison and White (2002)]. For example, banks may be tempted to make excessively risky and even negative net present value investments, which maximize the returns to equity at the expense of debt-holders or the deposit insurance fund.

The objective of capital regulation is to strengthen the soundness and stability of the banking system. However, some theoretical results suggest that banks may have found ways of overcoming the limitations that fixed 
capital requirements impose on their risk taking relative to their capital, either through asset substitution [Koehn and Santomero (1980), Kim and Santomero (1988), Flannery (1989), Rochet (1992)], the reduction of monitoring incentives [Bensako and Kanatas (1993), Boot and Greenbaum (1993)] or through substantial volumes of securitization [Jones (2000)]. In an inter-temporal model, Blum (1999) shows that under binding capital requirements, bank managers have an incentive to take risk this period in order to raise the costly additional unit of equity in the next period. Silva (2007) extends Blum's model to show that the risk-taking incentives are mitigated as intended, as long as the capital requirement are within certain threshold values. In the context of the 2008 crisis, Acharya and Richardson (2009) point out that a fundamental cause of the current wave of bank failures is that banks have engaged in a regulatory arbitrage by placing mortgages in off-balance sheet conduits and repackaging mortgages into mortgage backed securities (CDOs). They argue that the banks do this to take advantage of a regulation that allows them to hold reduced capital against such assets. The reduced capital in turn, allows the banks to multiply their loans which rendered the banks insolvent. Regulatory arbitrage is another form of responding to capital standards that eventually resulted in excessive amounts of systemic risk in the banking system.

Next, we explore the relationship between the bank's probability of default, the conditional volatility of stock returns and the asset volatility. While, the conditional volatility of stock returns is estimated using a GARCH process, the market value of the bank's assets and the associated level of volatility are not observable and hence cannot be computed directly. Merton (1977) provides a model that facilitates the estimation of market value of assets, asset volatility and the probability of default. The basic insight underlying this approach is that holding a bank's equity is equivalent to holding a call option on the bank's assets with an exercise price equal to the maturity value of the bank's debt. Alternatively, holding risky debt is equivalent to holding risk-free debt and writing a put option on the bank's assets.

In particular, assume that the market value of the bank's assets follows a continuous lognormal diffusion process with constant variance. If the bank's deposits are insured and hence pays a risk-free rate then the market value of equity for a bank is given as,

$E_{t}=V_{t} N(x)-B N\left(x-\sigma_{v} \sqrt{ } T\right)$

where,

$E_{\mathrm{t}} \quad=$ the market value of bank equity at time $\mathrm{t}$,

$V_{\mathrm{t}} \quad=$ the unobserved market value of the bank's assets at time $\mathrm{t}$,

$B \quad=$ the face value of the bank's debt

$T=$ time until the next bank examination date,

$\sigma_{\mathrm{v}} \quad=$ the unobservable instantaneous standard deviation of $d V / V$, and

$\mathrm{x} \quad=\left[\ln (V / B)+\left(\sigma_{\mathrm{v}}^{2} \mathrm{~T} / 2\right)\right] / \sigma_{\mathrm{v}} \sqrt{ } T$

$N() \quad=$. Cumulative Normal Distribution.

From Ito's lemma it follows that the standard deviation of the process $d E / E$ is given as

$\sigma_{E}=(V / E)(\partial \mathrm{E} / \partial \mathrm{V}) \sigma_{v}$

Given the above model, we can numerically solve for $V$ and $\sigma_{v}$ from equations (5) and (6). With these values we estimate the probability of default given as,

$$
P D=N\left(-d_{2}\right)
$$

where, $d_{2}=\frac{\ln (V / B)-0.5 \sigma_{v}{ }^{2} T}{\sigma_{v} \sqrt{T}}$. 
The above model has been subject to empirical scrutiny by many researchers. In the context of 14 major bank failures in the USA, Diba, Guo and Schwartz (1995) examine the net worth $(V-B)$ as estimated by the model and the FDIC's estimated resolution costs. They find that the model estimates are overvalued and is possibly because the model fails to capture many institutional details. Giammarino, Schwartz and Zechner (1989) examine a sample of Canadian banks to infer the market value of the bank's assets from the observed market value and volatility of its equity. The market value of assets is significantly different from the book value and is also different across banks. Based on the above model, these authors also compute risk-adjusted deposit insurance premiums. Chan-Lau, Jobert and Kong (2004) study the distance to default indicator for a sample of 38 banks from fourteen different emerging market countries during the period 1997 to 2003. They find that the distance to default measure reached its highest level around the time of the Asian crisis. They also found that the distance to default was significantly different for a sample of banks with a downgrade in credit rating compared to those that did not experience a downgrade.

The computation of the probability of default requires a measure of leverage (accounting data) as well as market data (market value of equity and its volatility). Due to the data limitation, the probability of default measure cannot be computed on a daily basis. In our paper, we use the second quarter accounting data reported in the S\&P Compustat and make a cross-sectional comparison between the probability of default, conditional volatilities and asset volatilities. The cross-sectional regressions are conducted on 5/22/2008 (low conditional volatility day) and on 7/18/2008 (high conditional volatility day).

With this in mind, we estimate the following model:

$$
P D=\alpha+\beta_{1}(\mathrm{Vol})_{i}+\beta_{2}(C A)_{i}+\beta_{3} \operatorname{Ln}(\text { Assets })_{i}+e_{i}
$$

where the independent variables in the regression are measures for Capital Adequacy $(C A)$, conditional volatility or asset volatility $(\mathrm{Vol})$, the natural $\log$ of total assets $(\ln ($ Assets $))$, and an error $(e)$. The summary statistics of the probability of default and the various independent variables are given in Table (1). The average market value of equity for high value banks is $\$ 9.4$ billion. The medium value banks have a much lower average of $\$ 0.23$ billion. The group of small banks has an average of $\$ 55.6$ million in equity. The implied market value of assets for our full sample of 344 banks is $\$ 13.0$ billion. This market value estimate far less compared to a book value of $\$ 86$ billion. The estimated market values of assets of the different sized banks are correspondingly lower than their average book value of assets. The medium valued banks have the lowest average value of Debt/Asset Value of $47.16 \%$, asset volatility of $36 \%$ and a probability of default of $7.62 \%$. Interestingly, relative to the medium valued banks, the high and low valued banks exhibited a slightly higher average value of Debt/Asset Value of $53.22 \%$ and $57.02 \%$, respectively. The medium valued banks correspondingly exhibit the lowest risk levels as measured by asset volatility, equity volatility and probability of default. If the high valued banks are too big to fail, it appears from the descriptive statistics that small banks are the most vulnerable among the three groups.

Table (1): This table presents the summary statistics for variables used in the cross-sectional regressions of conditional volatility and individual bank risk.

\begin{tabular}{|c|c|c|c|c|}
\hline Variables & Full & High Value ${ }^{1}$ & Mid Value & Low Value \\
\hline $\operatorname{MVE}(\$ m)$ & 3173.64 & 9471.79 & 233.24 & 55.65 \\
\hline Mkt Value of Assets ${ }^{2}$ & 13896 & 41263 & 1128 & 409 \\
\hline BV of Assets & 86070 & 255926 & 5692 & 3525 \\
\hline Debt/Value ${ }^{3}$ & 0.5247 & 0.5322 & 0.4716 & 0.5702 \\
\hline Asset Volatility $\left(\sigma_{\mathrm{v}}\right)$ & 0.37 & 0.39 & 0.36 & 0.37 \\
\hline Conditional volatility $\left(\sigma_{\mathrm{E}}\right)^{4}$ & 0.70 & 0.74 & 0.68 & 0.68 \\
\hline Probability of default & 0.1273 & 0.1649 & 0.0762 & 0.1409 \\
\hline
\end{tabular}

1. The sample of 314 banks was divided into three groups of approximately the same number of banks in each group. High (Low) value banks are those with the highest (lowest) market value of equity.

2. The asset value, probability of default and $\sigma_{\mathrm{v}}$ were estimated using the Merton model.

3. The book value of debt is obtained from COMPUSTAT, data item \#Q51.

4. The value of $\sigma_{E}$ is estimated using $\operatorname{GARCH}(1,1)$ from the returns data during 2007. 


\section{OLS regressions}

The results from the OLS regressions are presented in Table (2). Model 1 uses conditional volatility as the measure of bank risk and Model 2 uses asset volatility. We find that on a day when the industry average conditional volatility is low, the individual bank level conditional volatility does not significantly affect the individual bank's probability of default. However, individual bank level conditional volatility has a significant impact on the individual bank's probability of default when the average conditional volatility is high for the industry. This finding highlights the role of conditional volatility, both as an aggregate measure for the industry and as a measure of individual bank risk. The overall results indicate that the probability of default increases with conditional volatility, asset volatility and size. The probability of default decreases with the measure of capital adequacy. Each of the slope coefficients are significant at the $1 \%$ level and are consistent on the low volatility and high volatility day.

Table (2): This table presents results from the cross-sectional regressions of probability of default on individual bank risk characteristics for two models. These models differ only with respect to bank specific risk characteristic such as equity volatility and asset volatility. The cross-sectional regressions are conducted on 5/22/2008 (low conditional volatility day) and on 7/18/2008 (high conditional volatility day).

\begin{tabular}{lllll}
\hline Independent & $\begin{array}{c}\text { Low Conditional Volatility day (5/22/2008) } \\
\text { Model 1 }\end{array}$ & Model 2 & \multicolumn{2}{c}{$\begin{array}{c}\text { High Conditional Volatility day (7/18/2008) } \\
\text { Model 1 }\end{array}$} \\
\hline Intercept & 0.10860 & 0.05206 & $0.15158^{* *}$ & $0.21682^{*}$ \\
Cond Volatility & 0.04791 & - & $0.10289^{*}$ & - \\
Asset Volatility & - & $0.55042^{*}$ & - & $0.25248^{*}$ \\
MVE/Value & $-0.55310^{*}$ & $-0.67758^{*}$ & $-0.64585^{*}$ & $-0.81038^{*}$ \\
Ln(TA) & $0.03704^{*}$ & $0.03992^{*}$ & $0.03704^{*}$ & $0.03240^{*}$ \\
Adj $R^{2}$ & 0.5370 & 0.5707 & 0.6178 & 0.6607 \\
$F$ value & $122.02^{*}$ & $139.70^{*}$ & $169.63^{*}$ & $204.15^{*}$ \\
$N$ & 314 & 314 & 314 & 314 \\
\hline
\end{tabular}

Next, we compute the change in the probability of default from the low volatility day to the high volatility day and examine its relationship with changes in the independent variables. ${ }^{7}$ The results from the $O L S$ regressions are presented in Table (3). We find that the coefficients enter the regression in a predicted manner. A greater change in individual bank's conditional volatility (or asset volatility) results in a significantly larger change in the individual bank's probability of default. Changes in capital adequacy, however, has a significantly mitigating influence on the change in individual bank's probability of default.

Table (3): This table presents results from the cross-sectional regressions of probability of default on changes in individual bank risk characteristics for two models. These models differ only with respect to changes in bank specific risk characteristic such as equity volatility and asset volatility. The cross-sectional regressions are conducted for changes from 5/22/2008 (low conditional volatility day) to $7 / 18 / 2008$ (high conditional volatility day).

\begin{tabular}{lll}
\hline Independent & Model 1 & Model 2 \\
\hline Intercept & -0.04281 & $0.08389^{*}$ \\
Change in Cond Volatility & $0.15311^{*}$ & - \\
Change in Asset Volatility & - & $0.17843^{*}$ \\
Change in MVE/Value & $-0.57804^{*}$ & $-0.84596^{*}$ \\
Ln(TA) & 0.00154 & $0.00844^{*}$ \\
Adj $R^{2}$ & 0.4175 & 0.2911 \\
$F$ value & $75.79^{*}$ & $43.84^{*}$ \\
$N$ & 314 & 314 \\
\hline
\end{tabular}

\footnotetext{
${ }^{7}$ The value of $\ln$ (Assets) remains the same as both these dates are in the second quarter and the information on total assets is the same.
} 


\section{Robustness}

The $O L S$ regressions use the estimates of the probability of default, conditional volatility and asset volatility estimated from Merton's model. This could arguably yield results that may seem to be a tautology. We address this issue in the following steps and employ a logistic regression methodology;

a) First, we create a binary dependent variable. We compute the median value of the estimates of the probability of default estimated from equation (7). We interpret banks with values of $P D>$ median as risky banks and assign a value of 1 to the dependent variable. Banks with $P D<$ median are interpreted as safe banks and assigned a value 0 to the dependent variable.

b) Using the logistic regression technique, the binary dependent variable is regressed on the independent variables in equation (8).

c) The probability of firm $j$ being classified as a risky bank is computed from the coefficient estimates from the logistic regression model.

d) Finally, we compute Spearman's rank correlation between the values of $P D$ from equation (7) and the estimated probabilities from the logistic regression.

The regression results are presented in Table (4). We estimate two versions of equation (8); one characterized by low bank volatility (May 5, 2008) and the other a high volatility date (July 18, 2008). The result indicates that the probability of a bank being classified as a risky bank is positively related to the bank's conditional volatility and negatively related to capital adequacy (measured by the ratio of market value of equity to market value of the bank). This relationship holds regardless of whether the level of average conditional volatility of the industry is low or high. The results are significant at the $1 \%$ level of confidence.

The estimate of the probability that a bank is risky is given as $\mathrm{e}^{\mathrm{x}} /\left(1+\mathrm{e}^{\mathrm{x}}\right)$, where $\mathrm{x}=\alpha+\beta_{1}(C V)+\beta_{2}(C A)+$ $\beta_{3}(\ln (T A))$. We use the estimates of $\alpha, \beta_{1} \beta_{2}$ and $\beta_{3}$ from each of the regressions and compute the probability. The rank correlation between the probability estimates from the regression and the probability of default from Merton's model is 0.9355 for the low volatility day and 0.9252 for the high volatility day, both significant at the $1 \%$ level. The results from these cross-sectional regressions confirm that the conditional volatility of a bank is an important determinant of individual bank risk as measured by the probability of default.

Table (4): This table presents results from the cross-sectional logistic regressions of probability of default on individual bank risk characteristics with equity volatility as the proxy for bank specific risk characteristic. The cross-sectional regressions are conducted on 5/22/2008 (low conditional volatility day) and on 7/18/2008 (high conditional volatility day).

\begin{tabular}{lll}
\hline Independent & $\begin{array}{c}\text { Low Conditional Volatility Day } \\
(5 / 22 / 2008)\end{array}$ & $\begin{array}{c}\text { High Conditional Volatility Day } \\
(7 / 18 / 2008)\end{array}$ \\
\hline Intercept & 2.5702 & -0.1539 \\
Cond Volatility & $31.5754^{*}$ & $9.1059^{*}$ \\
MVE/Value & $-22.3985^{*}$ & $-17.2305^{*}$ \\
Ln(TA) & -0.2610 & 0.1894 \\
Test of global null & & \\
hypothesis that & & \\
coefficients =0 & Chi-Square & Chi-Square \\
Likelihood ratio & & $331.89^{*}$ \\
Score & $342.19^{*}$ & $198.96^{*}$ \\
Wald & $193.42^{*}$ & $50.00^{*}$ \\
$N$ & $45.24^{*}$ & 314 \\
\hline
\end{tabular}

\section{SYSTEMIC RISK, BANK SIZE AND CAUSALITY}

Large financial institutions are counterparties to other banks, so that losses at any one bank may cascade along a chain to other banks and beyond to financial markets and the macro economy [Kaufman (1996)]. For this 
reason, U.S. regulators have adopted a de facto "Too Big to Fail" (TBTF) policy. Ex ante, the uninsured investors in large financial institutions anticipate a bailout in the event of a failure. The implicit TBTF coverage for the uninsured creditors along with the Federal Insurance for the other depositors creates moral hazard incentive for managers of large banks. This means that in a systemic sense, large banks (more than smaller banks) have the incentive to take risks by investing in risky asset portfolios. The interconnectedness of large banks would imply that the greater riskiness of large bank stock returns causes an increase in the riskiness of small banks. In the context, we propose that the average conditional volatility of large banks tend to "cause" in the sense of Granger the conditional volatility of smaller banks and implement a Granger causality test.

Let $x_{L t}=\left\{\sigma_{L t}\right\}_{t=1}^{T}$ denote the time series of average daily conditional volatilities for $T$ days for a group of large banks. Let $x_{S t}=\left\{\sigma_{S t}\right\}_{t=1}^{T}$ denote a similar vector for small banks. Let the information set be denoted as $\left(x_{L t}, x_{S t}\right)$. Given this information set, $x_{L t}$ is 'Granger causal' for $x_{S t}$ if $x_{L t}$ helps predict $x_{S t}$. The following regression specification estimates the causal relationship

$$
x_{S t}=\beta_{0}+\sum_{j=1}^{J} \beta_{j} x_{S, t-j}+\sum_{k=1}^{K} \gamma_{k} x_{L, t-k}+u_{t}
$$

An F-test is used to examine the null hypothesis that the coefficients are equal to zero. We also test the following 'reverse' model to determine the direction of causality based on the level of statistical significance.

$$
x_{L t}=\beta_{0}+\sum_{j=1}^{J} \beta_{j} x_{L, t-j}+\sum_{k=1}^{K} \gamma_{k} x_{S, t-k}+u_{t}
$$

We used the algorithm called 'Granger Cause' available in the MATLAB central. This algorithm requires the specification of the two time-series vectors, the significance level and the maximum number of lags to be considered. The algorithm chooses the optimal lag length for the vectors based on the Bayesian Information Criterion and yields an F-statistic along with the corresponding critical value.

We examine the relationship between the cross-sectional average (daily) conditional volatilities across high, medium and low valued banks. Consider Figure (4).

The volatility clusters identified earlier in Figure (1) are contributed by each of the three different sized groups of banks. The average conditional volatility of the high valued banks is the highest in each of the three volatility clusters. During periods of relatively low volatility in 2008 , the conditional volatility of high valued banks declined the most and was the lowest among the three groups. These observations suggest that the volatility of high value banks is very high and consistent with the idea that big banks have a greater propensity to take risk. Interestingly, the conditional volatility of low valued banks is higher than the medium valued banks during the period under consideration. This non-linear relation between size and volatility was reported earlier in the summary statistics in Table (1). Our analysis suggests that the risky high valued banks combined with the TBTF doctrine is likely to adversely small banks. However, this argument depends on whether the volatility of high valued banks causes the medium and small banks to be risky, as well.

We conduct Granger causality tests for each pair of the time-series vectors of conditional volatilities among the three groups. The results are reported in Table (5). 
Figure (4): This figure plots the cross-sectional average conditional volatility during the first 180 trading days in 2008 for 115 high equity valued banks, 114 medium equity valued banks and 115 low equity valued banks.

\section{Conditional Volatility Based On Firm Size}

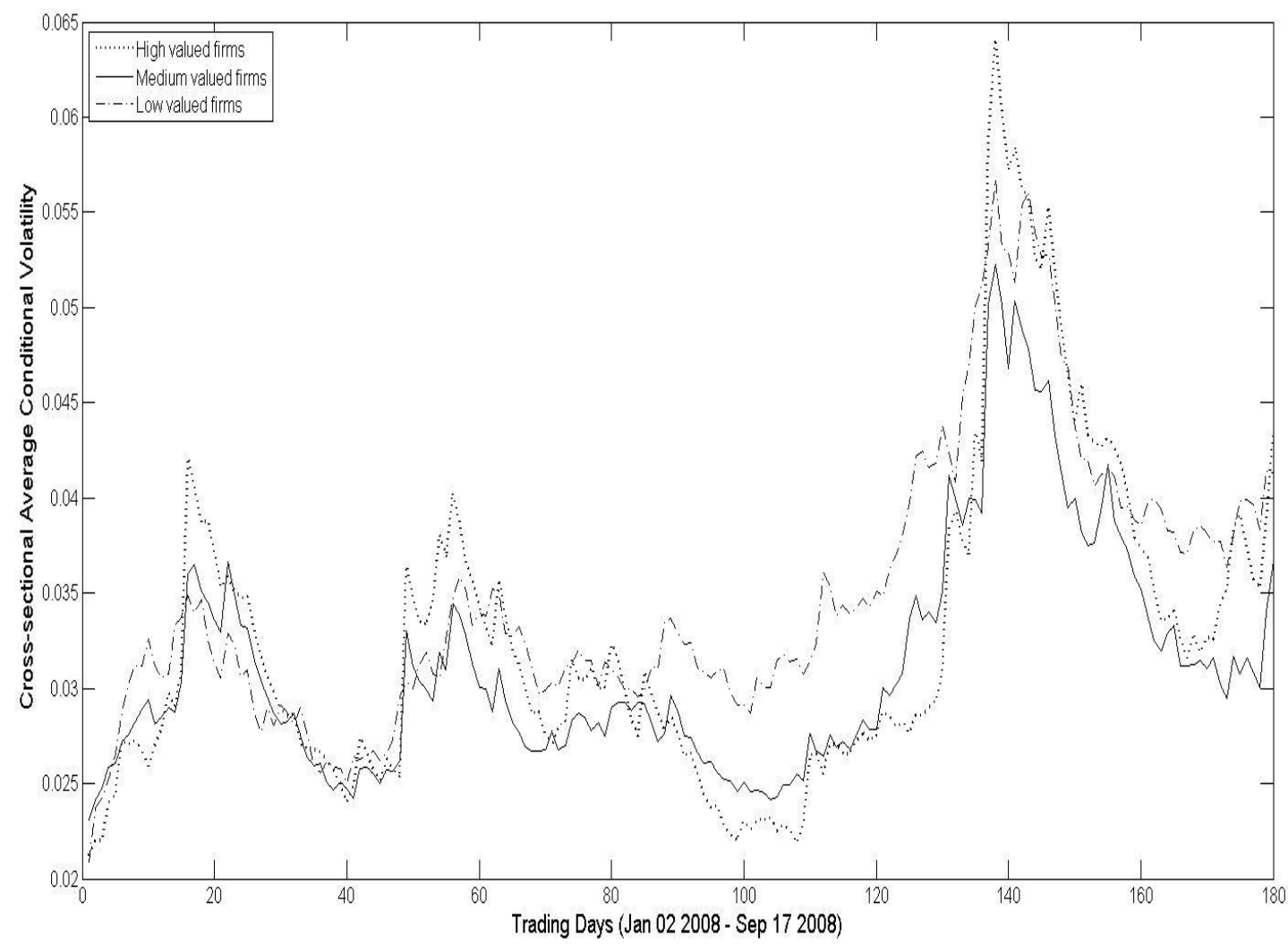

Table (5): This table presents the results from the Granger causality test. The sample of 344 banks is divided into three groups based on the market value of equity. The group with the highest values is called 'High' and the group with the lowest values is called 'Low'. The rest of the banks are called 'Mid'. These tests use a lag of 5 days and a significance of $1 \%$. We employed a MATLAB program called Granger_cause. The symbol ' $\rightarrow$ ' in the table indicates the direction of causality.

\begin{tabular}{llll}
\hline Group $\mathbf{A} \rightarrow$ Group B & F-value & Critical value & Decision \\
\hline High $\rightarrow$ Low & 14.6634 & 6.7802 & Reject Null \\
Low $\rightarrow$ High & 4.8594 & 6.7802 & Do not reject \\
High $\rightarrow$ Med & 16.3344 & 6.7802 & Reject Null \\
Med $\rightarrow$ High & 3.3076 & 6.7802 & Do not reject \\
Low $\rightarrow$ Med & 0.6379 & 6.7802 & Do not reject \\
Med $\rightarrow$ Low & 5.6120 & 6.7802 & Do not reject \\
\hline
\end{tabular}

The results indicate that the average conditional volatility of high valued banks 'Granger Causes' the average conditional volatility of small and medium banks as indicated by F-values far exceeding the critical value. This implies that the small and medium banks' risk level is influenced and can be predicted at some level based on the risk level of high valued banks. The results also indicate that there is no reverse causality between low and medium valued banks and high valued banks. In addition, there is no evidence of Granger Causality between low and medium valued banks. These are denoted by lower than critical values of the F-statistic. These results suggest that the measure of conditional volatility indicates that the systemic risk in the commercial banking sector, during the initial half of 2008 , is mainly caused by big banks. 
Table (6): This table presents the list of the most risky 15 banks, on the day with the highest average conditional volatility in clusters A, B and C during the first 180 days in 2008.

\begin{tabular}{|l|l|l|}
\hline \multicolumn{1}{|c|}{ Cluster A } & \multicolumn{1}{c|}{ Cluster B } \\
\hline Bank Holdings The & Capital Corp Of The West & \multicolumn{1}{c|}{ Cluster C } \\
Community West Bancshares & National City Corp & Vineyard National Bancorp \\
Irwin Financial Corp & Irwin Financial Corp & Cuntington Bancshares Inc \\
E Trade Financial Corp & Central Valley Comm Bancorp & Wachovia Corp 2nd New \\
Optimumbank Holdings Inc & Bank Of Virginia & East West Bancorp Inc \\
C C F Holding Company & Severn Bancorp Inc Md & Carolina Bank Holdings Inc \\
Capital Bank Corp New & Bank Mckenney Va & Tennessee Commerce Bancorp Inc \\
F P B Bancorp Inc & Sierra Bancorp & Provident Bankshares Corp \\
Popular Inc & Western Alliance Bancorporation & Colonial Bancgroup Inc \\
Amcore Financial Inc & Doral Financial Corp & Bankatlantic Bancorp Inc \\
Western Alliance Bancorporation & C \& F Financial Corp & Cape Fear Bank Corp \\
Independent Bank Corp Mich & United Community Banks Inc Ga & South Finl Group Inc \\
Central Valley Comm Bancorp & I C I C I Bank Ltd & E Trade Financial Corp \\
Doral Financial Corp & E Trade Financial Corp & Amcore Financial Inc \\
Citizens Republic Bancorp Inc & Security Bank Corp & Columbia Bancorp Ore \\
\hline
\end{tabular}

\section{CONCLUSION}

This research proposes average conditional volatility as a measure of systemic volatility for the U.S. commercial banking industry. This measure is easy to compute and requires only the daily stock returns data for commercial banks. The average conditional volatility is largely influenced by the cumulative performance of all banks through the values of lagged average conditional volatilities. A smaller fraction of the average conditional volatility is contributed by the most recent performance of all banks. In this sense, the average conditional volatility captures the systemic nature of risk.

Our research shows that the average conditional volatility in 2008 is consistently higher than the volatility in 2007, thus indicating a systemic increase in risk. The conditional volatility also serves as an early warning of a volatile system as seen from Clusters A and B in Figure (1). A closer examination indicates that the list of 15 most risky banks on the highest volatility day is different across the three clusters [See Table (6).] This observation is consistent with Bartholomew and Whalen (1995) and is a reflection of the systemic nature of increased risk being spread out to various banks and is not confined to a few. Another systemic relationship we observe is that high (equity) valued banks influence the riskiness of medium and smaller banks. Cross-sectional regressions indicate that individual bank's probability of default is unrelated to the bank's conditional volatility during times of low, industry wide risk (as measured by average conditional volatility). However, the bank's conditional volatility significantly affects its probability of default when the industry is experiencing a high level risk. Regardless of the industry level risk, a bank's probability of default has a significant negative relation with its capital adequacy (as measured by the proportion of equity capital). Additionally, at an aggregate level, Granger causality tests indicate that the conditional volatility of 'big' banks causes the riskiness of medium and small banks to increase.

The subject of systemic risk in the banking industry has been a topic of concern, debate and study for many decades. The need to measure and control systemic risk is more acute now than in the past because of increased interdependencies imposed by structured products and risk insurances. The need for a cushion of funds and the resulting capital standards have been the domain of regulatory agencies in controlling the riskiness of individual banks and consequently the systemic risk in the banking industry. A drawback of capital regulations is that its enforcement depends on bank audits occur very infrequently. Measures of individual bank risk and the expected loss to the fund were contributions made since the advent of option pricing techniques. These techniques, however, required data inputs from accounting statements that are, at best, only available on a quarterly basis. Despite the availability of the arsenal mentioned above, most of the stakeholders had no any early warning of the 2008 crisis. We show that the conditional volatility measure contributed by Engle (1982) has the desired features of a systemic risk measure and does provide the stakeholders with an early warning of increased systemic risk. 


\section{ACKNOWLEDGEMENTS}

We thank Dr. Jayashree Harikumar Physical Sciences Laboratory, New Mexico State University, for her help with using Matlab.

\section{REFERENCES}

1. Acharya,V.V., Pedersen L.H., Philippon, T., and Richardson, M.P., (2010) Measuring Systemic Risk, Available at SSRN: http://ssrn.com/abstract=1573171

2. Acharya, V.V.and Richardson, M.P. (2009), Causes of the Financial Crisis, Critical Review, Vol. 21, Nos. 2 \& 3, pp. 195-210. Available at SSRN: http://ssrn.com/abstract=1514984

3. Bartholomew, P.F. and G.W. Whalen (1995), Fundamentals of Systemic Risk, in Kaufman, G. (ed.), Banking, Financial Markets, and Systemic Risk, Greenwich, 3-18.

4. Bensako, D. and Kanatas, G. (1993), "Credit Market Equilibrium with Bank Monitoring and Moral Hazard", Review of Financial Studies, 213-232

5. Bollerslev,T., (1987), Conditionally heteroskedastic time series model for speculative prices and rates of return, The Review of Economics and Statistics 69, 542-547.

6. Bollerslev, T., Chou, R.Y and Kroner, K.F. Kroner, (1992), ARCH modeling in finance: a review of the theory and empirical evidence, Journal of Econometrics 52, 5-59.

7. Bikhchandani, S and Sharma, S, (2000) Herd Behavior in Financial Markets: A Review, IMF Working Paper No. 00/48. Available at SSRN: http://ssrn.com/abstract=228343 or doi:10.2139/ssrn.228343

8. Blum, J. (1999), "Do Capital Adequacy Requirements Reduce Risk in Banking?", Journal of Banking and Finance 23, 755-71

9. Boot, A. and Greenbaum, S. (1993), "Bank Regulation, Reputation and Rents Theory and Policy Implications". In Mayer, C., Vives, X. (eds) Capital Markets and Financial Intermediation. Cambridge University Press, Cambridge 262-285

10. Brownlees, C.T., and R. Engle, (2010), "Volatility, Correlation and Tails for Systemic risk Measurement," Electronic copy available at: http://ssrn.com/abstract=1611229

11. Chan-Lau, J. A., Jobert, A. and Kong J. Q. (2004), An Option-Based Approach to Bank Vulnerabilities in Emerging Markets, IMF Working Paper No. 04/33 (Washington: International Monetary Fund).

12. Chan-Lau, Jorge and Syl, Amadou N. R. (2006) "Distance-to-Default in Banking: A Bridge Too Far?” IMF Working Paper

13. Christie, W. G., and Huang, R. D., (1995), "Following the pied piper: Do individual returns herd around the market? Financial Analyst Journal, Vol. 51 (4), pp. 31-37

14. Diba, B., Guo, C.H., Schwartz, M., (1995). Equity as a call option on assets: some tests for failed banks. Economics Letters 48, 389-397.

15. Duan, J. C., and Wei, J.Z., 1999, "Pricing Foreign Currency and Cross-Currency Options under GARCH", Journal of Derivatives, Fall, 51-63.

16. Engle, R.F., (1982), Autoregressive conditional heteroskedasticity with estimates of the variance of U.K. inflation, Econometrica 50, 987-1008.

17. Flannery, M. (1989), "Capital Regulation and Insured Bank.s Choice of Individual Loan Default Rates", Journal of Monetary Economics.

18. Gennotte, Gerard and Pyle, David (1991)“Capital controls and bank risk,” Journal of Banking \& Finance, 15(4-5): 805-824 .

19. Giammarino, R., Schwartz, E. and Zechner, J. (1989). Market Valuation of Bank Assets and Deposit Insurance in Canada. Canadian Journal of Economics $22: 109-127$.

20. Gray, D.F., and Jobst, A.A.,(2009), Tail Dependence Measures of Systemic Risk Using Equity Options Data - Implications for Financial Stability, Forthcoming Working Paper, International Monetary Fund (IMF), Washington, D.C.

21. Gray, D.F., Merton, R.C., and Bodie, Z, (2008), New Framework for Measuring and Managing Macrofinancial Risk and Financial Stability, Working Paper No. 09-015 (Cambridge, Massachusetts: Harvard Business School, August).

22. Jones, D. (2000), "Emerging Problems with the Basel Capital Accord: Regulatory Capital Arbitrage and Related Issues", Journal of Banking and Finance, 24 (1-2), 35-58. 
23. Hansen, P. Reinhard and Lunde, A., 2001, “A Forecast Comparison of Volatility Models: Does Anything Beat a GARCH(1,1)?” WP No. 01-01, Department of Economics, Brown University.

24. Kaufman, G.G, (1996) Bank failures, Systemic risk, and bank regulation, Cato Journal Spring/Summer, pp $17-45$.

25. Kaufman, G.G., and Scott K.E. (2003) What Is Systemic Risk, and Do Bank Regulators Retard or Contribute to It? The Independent Review, v. VII, n. 3, Winter 2003, 371-391.

26. Kim, D. and Santomero, A.M. (1988), "Risk, Banking and Capital Regulation", Journal of Finance 43, 1219-33

27. Koehn, M. and Santomero, A.M. (1980), "Regulation of Bank Capital and Portfolio Risk", Journal of Finance 35, 1235-50

28. Lehar, A., (2005), Measuring systemic risk: A risk management approach, Journal of Banking and Finance, vol. 29, 2577-2603.

29. Marcus, A.J. and Shaked, I., (1984) 'The valuation of FDIC deposit insurance using option pricing estimates.' Journal of Money, Credit and Banking 16, 446-60

30. Merton, R.C. (1973) Theory of rational option pricing. Bell Journal of Economics 4, 141-83

31. Merton, R.C. (1977) An analytic derivation of the cost of deposit insurance and loan guarantees. Journal of Banking and Finance 1, 3-11

32. Morrison, A.D. and White, L., (2002) Crises and Capital Requirements in Banking, Oxford Financial Research Center Working Paper No. 2002-FE-05. Available at SSRN: http://ssrn.com/abstract=312964 or doi:10.2139/ssrn.312964

33. Rochet, J.C (1992), "Capital Requirements and the Behavior of Commercial Banks", European Economic Review, 36, 1137-78.

34. Schwarcz, S.L., (2008) Systemic Risk. Duke Law School Legal Studies Paper No. 163; Georgetown Law Journal, Vol. 97, No. 1, 2008. Available at SSRN: http://ssrn.com/abstract=1008326

35. Shumway, Tyler and Sreedhar T. Bharath, (2008) "Foreasting Default with the Merton Distance to Default Model," Review of Financial Studies, 21(3): 1339-1369.

36. Sliva, N., (2007) Capital Regulation and Bank Risk Taking: Completing Blum's Picture, Central Bank of Chile, Working Paper, $\mathrm{N}^{\circ} 416$. 
NOTES 